DOI: $10.20472 / B M .2019 .7 .1 .004$

\title{
INTERORGANIZATIONAL RELATIONS AND ORGANIZATIONAL CAPABILITIES IN INTERNET OF THINGS BUSINESSES
}

\author{
FUMIHIKO ISADA, YURIKO ISADA
}

\begin{abstract}
:
The purpose of this research is to quantitatively clarify interorganizational relations and organizational capabilities suitable for loT (Internet of Things) business. Moreover, we also proposed to look for the reasons why Japanese loT-related businesses are not necessarily successful. According to prior research, it is thought that open innovation is useful in loT business. This is because system cooperation and various types of technological knowledge are required of IoT business. Then, there are two general possibilities for the form of open innovation: selection with a large network and a narrow network. That there is much opportunity for outside encounters increases the opportunity for innovation. On the other hand, in reducing the number of cooperation partners and investing strategically in business resources, the success rate of a technological development may increase. Moreover, to utilize an open innovation, an organizational capability that fits an open innovation may be required. According to previous research, in interorganizational relations, selective ability and integration capability are important. It is thought that a high level of selective ability is very important. As compared with typical businesses, it is thought that there is much opportunity to select an external technology in which a company is inexperienced. On the other hand, it is also thought that the integration/coordination ability to advance the cooperation process steadily against the uncertain technology challenges among external organizations becomes important. As a methodology, a questionnaire was carried out to IT-related companies that undertake IOT business. As a result, the character of the interorganizational relations and the organizational capabilities related to profitability in loT businesses became clear. The study also showed the challenge against organization management of the former type of Japanese firm.
\end{abstract}

\section{Keywords:}

interorganizational relations, organizational capabilities, loT-related businesses, large network, deep network, selection capability, integration capability

JEL Classification: 032

\section{Authors:}

FUMIHIKO ISADA, The Faculty of Informatics, Kansai University, Japan, Email: isada@kansai-u.ac.jp YURIKO ISADA, School of Policy Studies, Kwansei Gakuin University, Japan, Email: yuriko@kwansei.ac.jp

\section{Citation:}

FUMIHIKO ISADA, YURIKO ISADA (2019). Interorganizational relations and organizational capabilities 
in Internet of Things businesses. International Journal of Business and Management, Vol. VII(1), pp. 48-62., 10.20472/BM.2019.7.1.004 


\section{Introduction}

The purpose of this research is to quantitatively clarify interorganizational relations and organizational capabilities suitable for loT (Internet of Things) business.

At present, IoT businesses are attracting considerable attention and are rapidly advancing. In Europe, Industry 4.0 and other trends in automation are mentioned as similar notions. Transformations in information and communication technologies before the loT included advances in computing, the spread of the Internet, and so on. The loT directly concerns autonomy and the advanced features of all devices in a process termed 'smartization'. The impact of the loT on changes in industrial structure is important. Myriad devices collect big data autonomously. Big data are shared by the Internet as a database and are analysed through artificial intelligence. Moreover, various devices are controlled automatically and in an integrative fashion.

Porter and Heppelmann (2014) analysed the loT using several examples. For instance, a farm tractor evolves from a stand-alone farming implement into a complex system of agricultural automation. It is thought that the impact of the loT on industrial structure is considerable and its coverage is wide. The loT constitutes a significant business opportunity. Moreover, many companies are beginning to enter the area of loT business all at once and all around the world, and competition in terms of technological development is extremely high. For a company to produce excellent results from research in the context of such a competitive environment, with rapid technological development, it is necessary to increase both the speed and efficiency of research and development $(R \& D)$.

Recently, open innovation (Chesbrough, 2003) has attracted attention as a means of enhancing the efficiency and speed of R\&D. That is, it is a strategy that promotes innovation through cooperation with an external organization, leveraging the specific technical resources of the company. It is thought that speeding up development and its correspondence with various areas can be attained through open innovation, using the technology of an external organization. In carrying out business in the loT field, there are related technical factors, for example ensuring cooperation among various systems in terms of hardware, software, network communications, and database applications. To enable such cooperation, there is a need for technology, such as information and telecommunications, analysis, and security. It is difficult for a single company to bring these various technical developments to bear simultaneously. It is thought that by cooperating with many companies, excellent research results can be produced

However, if a company depends too greatly on external technology, there is a risk that the company-specific capability to create technology may decline. If the technological capabilities of the company decline, there is also a risk that the capability to understand external technology and to utilize it may decline. Therefore, the need to increase the level of cooperation and extend the research area is not necessarily linked to the results of research.

Moreover, to utilize an open innovation, an organizational capability that fits an open innovation may be required. For example, the long-term nature and the close nature are raised as main characters of the interorganizational relation of the conventional Japanese firm. The typical example is the keiretsu intragroup dealings between a vehicle manufacturer and a car parts manufacturer group. And an organizational capability important for keiretsu is coordination capability. The finished product of automobiles consists of many components whose 
interrelationships are complicated. A capital and personnel exchange is densely performed in a keiretsu, which requires a strong fiduciary relation and successful coordination. Such a dense relationship promotes research and development and cost cutting, attaining high productivity. That is, it is to bring about high performance that organizational capabilities such as organizational structure and management fit interorganizational relations. Moreover, since it is hard to observe organizational capability from outside the company, an organizational capability is hard to be copied from a competitor, and it can become a continuous competitive advantage. On the other hand, since an organizational capability is achieved gradually and has inertia, it has the character of being hard to change. This may cause the problem that an old conventional company and organization are hard to correspond to the rise of a new industry like the loT. This research quantitatively clarifies these issues based on a questionnaire to companies that are currently tackling loT business.

\section{Precedent research}

\section{2-1. Competitive advantage in loT business}

To argue about the organizational structure and organization management in loT business, the competitive advantage of loT business is first considered. If the source of this advantage is determined, the means for improving it may become clear.

According to Porter and Heppelmann (2014), the phrase 'Internet of things' has arisen to reflect the growing number of smart, connected products and highlight the new opportunities they can represent. Yet this phrase is not very helpful in understanding the phenomenon or its implications. The Internet, whether involving people or things, is simply a mechanism for transmitting information. What makes smart, connected products fundamentally different is not the Internet, but the changing nature of the 'things'. It is the expanded capabilities of smart, connected products and the data they generate that are ushering in a new era of competition. Companies must look beyond the technologies themselves to the competitive transformation taking place.

Moreover, according to Porter and Heppelmann (2015), the new capabilities of smart, connected products alter every activity in the value chain. At the core of what is reshaping the value chain is data. As the ability to unlock the full value of data becomes a key source of competitive advantage, the management, governance, analysis, and security of that data are developing into a major new business function.

That is, data constitute a scarce resource that can serve as a source of competitive advantage in loT business, and it is thought that business systems centring on data improve a competitive advantage. The increasing capabilities of smart, connected products not only reshape competition within industries but expand industry boundaries. This occurs as the basis of competition shifts from discrete products, to product systems consisting of closely related products, to systems of systems that link an array of product systems together (Porter \& Heppelmann, 2014).

\section{2-2. Open innovation}

According to Chesbrough (2003), conventional innovation has been performed primarily through a vertical integration model in one industrial group. However, in terms of the speed of the transmutation of management environments, for example resulting from the development of a technique or the diversification of a market, innovations will support these developments in a network of various companies. Innovation involves a high level of uncertainty and entails a 
necessary process of trial and error. The greater the divergence that a player brings to the process of innovation, the more instances of trial and error will be generated by the various players. There are many ways for innovation to be achieved. The greater the diversity of different kinds of attempts at innovation, approaching problems from different perspectives, such as the external viewpoint, the user's viewpoint, the viewpoint of a different society, or the viewpoint of a different culture, the more it is thought that innovation can be facilitated.

Dittrich, Duysters, and de Man (2007) described the different approaches in a joint research network as comprising an exploitation strategy and a pursuit strategy. In an exploitation strategy, an alliance partner has a funding relationship, generally related to the same technological or business field. It is rare for a new alliance partner to participate in a collaborative network, and the speed with which an alliance partner changes is slow. An exploitation strategy is similar to a closed innovation, in which a development is made in an originally outstanding field mostly with a specific partner. In a pursuit strategy, an alliance partner does not have a funding relationship and is in many cases in a different technological or business field. In the pursuit strategy, many new alliance partners participate in a collaborative network, and alliance partners change rapidly.

\section{2-3. A large network}

Granovetter (1973) argued that for diffusion across a network, weak ties are most valuable. According to Granovetter (2005), interpersonal ties generally come in three varieties: strong, weak, or absent. Weak social ties, it is argued, are responsible for the majority of the embeddedness and structure of social networks in society, as well as the transmission of information through these networks. Specifically, more novel information flows to individuals through weak rather than strong ties. As close friends tend to move in the same circles, the information they receive overlaps considerably with what is already known. Acquaintances, in contrast, know people in other circles and thus receive more novel information.

According to Badaracco (1991), a strategic alliance is divided into product links and knowledge links. Generally, product links are formed in many cases to fill the gap of the product portfolio of a company. A company achieves cost cutting, diversification of risk, and shortening of lead time by product links. On the other hand, knowledge links are formed when a company is going to access the knowledge of the other company and create new knowledge together. With knowledge links, new knowledge can be built in the domain of the company. Moreover, knowledge links with many external companies are strengthened mutually and contribute to the long-term strategy of each company.

According to Powell, Koput, and Smith-Doerr (1996), an innovation is produced not by an independent organization but by a network in industries where specialized knowledge is widely distributed over the network among organizations. The biotechnology industry serves as an example. There is a significant quantity and variety of R\&D in biotechnology companies, which occupies a central position in the network alliance.

Langlois and Robertson (1992) explained the benefit of modularizing a product and an industrial network from the viewpoint of organization economics. Making decisions regarding the insourcing or outsourcing of the components for a product is dependent on the relationship between the cost of internalization to the organization and the transaction cost. If the product is integrative, a company with a vertical integration mode of operation, in which it is easy to carry out coordination, will be at an advantage as the transaction cost within a market exceeds the 
internalization cost. However, if a product is modular, it is difficult to attain innovation in a single firm without marring the interchangeability between modules; that is, the internalization cost exceeds the transaction cost. Therefore, in this situation, it is desirable to supply a component from the outside. Moreover, vertical specialization, which a modular style promotes, also encourages the construction of a manufacturer's network. In a non-centralized power network such as this, the manufacturer of a component, a user, and an assembler can determine the standard required through the process of the market or negotiation. The horizontal network of such companies may actually bring an innovator a higher profit than the monopolistic profit that an innovator can enjoy through patenting. The network realized by modularization can expand the overall market. Therefore, the profitability of the business concentrated on a specific component in an expanded market may be superior to the niche monopoly that is the exclusive business of a vertically integrated company.

\section{2-4. A narrow network}

According to Krackhardt (1992), there are some problems in the Granovetter definition. There are subjective criteria in the definition of the strength of a tie such as emotional intensity and the intimacy. Strong ties are very important in severe changes and uncertainty. According to Coleman (1988), dense network structure promotes good communication.

Uzzi (1997) stated that if there is a fiduciary relation in the interorganizational relation, a prior and subsequent transaction cost, such as a complicated contract and monitoring of corporate activity, may be saved. A fiduciary relation reduces uncertainty and provides easy disclosure of confidential communications and the investment that specialized in the transaction among partners. Confidence is formed by partners' reciprocity and face-to-face interaction. The keiretsu intragroup dealings in the relationships among Japanese companies have a mechanism of governance by confidence. The strong high-density network among organizations supports keiretsu intragroup dealings.

According to Imai, Itami, and Koike (1982), the rationale for coordination in a market is primarily based on price, whereas the rationale in an organization is authority or the order of relationships based on a hierarchy. From the viewpoint of mutuality among participants, entry or withdrawal from a market is straightforward, and an organization is characterized by being fixed and continuous. The market mechanism and the principle of organization each have a relative advantage according to the trade environment and the characteristics of the goods being traded. As an interim mode, there is an intermediate organization, which is the network type, such as keiretsu and strategic alliance. There are various types of networks that connect economic agents, reflecting the strength of the connection, duration, and so on. An intermediate organization is considered to be an eclectic mode that addresses the weaknesses of the market or the business organization.

According to Dyer and Singh (1998), the earnings that a corporate network brings about are called relational rent. Relational rent is a surplus of benefits by collaboration. The sources of relational rent are relation-specific assets, knowledge-sharing routines, mutually complementary ability, and effective governance.

\section{2-5. Integration capability}

Christensen (2006) defined organizational capability as special technical and integration capabilities. The special technical capability is the team's basic capacity to mobilize resources for 
a specific production activity. Integration capability is a high-level administrative ability that mobilizes, cooperates in, and develops exchangeable resources or capabilities, yielding value and competitive advantage at the system level. Thus, special technical capability is promoted through the resources inside an organization, whereas integration capability serves as the central resource of open innovation, and organizational boundaries may differ according to managerial resources.

Henderson and Cockburn (1994) classified R\&D capability into local capability and architectural competence. They then explored the relevance of organizational capability and the outcome of research on pharmaceutical products in terms of the development of drugs for circulatory organs in a European and US pharmaceutical company. Local capability is the fundamental individual capability and knowledge for everyday problem solving. Architectural competence concerns the ability to use and unify local capabilities effectively and create new local capabilities that may be needed. The research claims that architectural competence, which is an organizational capability in connection with the integration and combination of information or knowledge from inside and outside an organization, is an important source of competitive advantage for a company.

The significance of vigorously promoting a departmental and technical field exchange across boundaries has been pointed out also in the innovation of assembly products. For example, this was the argument of lansiti and Clark (1994), which focused on the product-development activities of a motor industry and computer industry. lansiti and Clark (1994) regarded the capability to integrate the various resources on businesses on the inside and outside of the organization as the leading source of product innovation. The integration capability of an organization consists of three elements: customer integration, which is the capability to reflect customer knowledge in new products; technology integration, which is the capability to unite various technologies; and internal integration, which is the capability to coordinate the various departments in organization. lansiti and Clark also investigated the contribution of each element to the product innovation of both industries. As a result, in an automobile company, high correlation was observed among customer integration, internal integration, and development performance. Moreover, technology integration and internal integration were strong in the company, which is competitive through the development of a mainframe computer. According to lansiti and Clark (1994), it heightens the integration capability of an organization when various departmental and technical fields in connection with a product innovation alternate actively over the wall of the organization, and the integration capability contributes to a product innovation.

\section{2-6. Selection capability}

According to Dyer and Kale (2007), the organizational capability in connection with an alliance is classified into two kinds. One is the capability to obtain the information of external organizations correctly, to select it, to share the clear alliance purpose with external organizations, and to enter into cooperation. Another is the capability to advance the alliance, making mutual the mechanisms of sharing information and forming agreements.

Hoffman and Schlosser (2001) divided the factor affecting the success or failure of an alliance into the content variable and the process variable in the empirical study of an alliance. A content variable is a variable about the conditions before an alliance, and a process variable is a variable about the execution of an alliance. 
According to previous studies, 'exploration' and 'exploitation' are contrasting styles of organizational learning, and exploration tends to be neglected if the focus is put on exploitation (Levinthal \& March, 1993; March, 1991; Stuart \& Podolny, 1996). However, in recent years, cases have been observed in which the technology search function has separated from the R\&D organization. Search activities are promoted by separating the technology search organization from the present organizational process (Christensen, 1997; Goold \& Campbell, 2002; Raisch et al., 2009). The technology search organization that becomes a contact with the outside company can solve a technology challenge under the environment of high uncertainty (Goold \& Campbell, 2002).

According to Fujimoto and Nobeoka (2004), the product architecture is a fundamental strategy that divides a product and a process into a module, distributes a product function, and designs and adjusts the interface among components. The product architecture is divided into an integral type and a modular type (Baldwin \& Clark, 2000; Ulrich, 1995). In an integral type, unless it adjusts and optimizes the design of components mutually for every product, the performance of the whole product does not come out. In a modular type, the interface of components and a module has fundamentally standardized, and various products are made only by gathering up the present components.

The degree of integrality of a product or a process is concerned with the interdependence among the elements that constitute a product and a process. The organizational process of designing and developing the product of the integral type architecture, which is a complicated interdependence, tends to need close mutual cooperation and dense communication. For that purpose, an organizational structure also needs to develop the mechanism of mutual coordination among departments. That is, the organization treating the integral type architecture increases competitiveness by having an integrative organizational capability. For example, according to Fujimoto and Nobeoka (2004), the Japanese 'Toyota system' is a typical integrated type of organizational capability, and this progressed in integral architecture products like the car with a monocoque body. The organizational capability of many conventional Japanese firms has an advantage in integration capability, fitted with the product and process of the integrated type architecture.

On the other hand, according to Fujimoto and Nobeoka (2004), in contrast to modular architecture, the capability to select a system element or the capability to conceive of the rule of the whole system in advance corresponds. Generally in a modular system, performance of a whole system is realized by gathering up the modules, which function independently according to the interface rule among the modules set up in advance (Baldwin \& Clark, 2000). Therefore, if the best components (modules) are selected and gathered up functionally, the whole can become the best product and process. That is, the organizational capability, which is suitable for the modular architecture and brings about competitiveness, is the capability to correctly select each product element and process element, and is the capability to judge a system configuration. Moreover, in the process in which a modular system is generated, the organizational capability as the system architect or designer who conceives of a module interface rule in advance is required (Aoki, 2002)

\section{Survey hypothesis}

Based on the precedent research above, survey hypotheses were established. 
First, with respect to loT business, an important source of competitive advantage is considered to be high-quality data as a scarce resource. loT business is usually formed across boundaries among various industries. In loT business, the data, which have utility value across boundaries in a multi-industry environment, may generate network effects. That is, the business model that combines an industrial element centring on data can serve as a source of value added, rather than each industrial element. Thus the competitive advantage of a company may be holding quality data. Moreover, the processing technology and the organizational control of the data in an advanced technical field cannot easily become a commodity. Therefore, it is thought that high data acquisition capability and high data analysis ability improve profitability for an loT business.

H1. In loT business, a high level of data acquisition capability improves profitability.

H2. In loT business, a high level of data analysis ability improves profitability.

Next, according to prior research, it is thought that open innovation is useful in loT business. This is because system cooperation and various types of technological knowledge are required of loT business. Then, there are two general possibilities for the form of open innovation: selection with a large network and a narrow network.

That there is much opportunity for outside encounters increases the opportunity for innovation. In particular, an encounter with external knowledge of a different kind can improve a possibility that an innovation will be produced. If the innovation is produced and is successful, profitability may increase. If the degree of technological standardization and modularization is large, the effect of cooperation with the outside may easily produce further increases. Various forms of external cooperation are used, such as an industrial cluster or a technology consortium from the past. Furthermore, in today's business, various new methods of cooperation with external organizations are used to advance technical environments such as the Internet. For example, a method like a 'sharing economy' is expanding in usage. With new methods, various external organizations can now cooperate quickly, with low cost.

On the other hand, the predominance of a narrow network is also considered. Increasing the number of cooperative arrangements can break up business resources such as advanced engineering and investment capital. If business resources break up, the productivity from cooperation may fall. Moreover, development of new technology has special high uncertainty.

It is risky to invest large business resources in highly uncertain technology in cooperation with external organizations. Probably a fiduciary relationship with external organizations must be required to make an investment with a big risk. In reducing the number of cooperation partners and investing strategically in business resources, the success rate of a technological development may increase. The deep network established through a strategic partnership with a specific company may be effective.

H3. In loT business, a large network with external organizations improves profitability.

H4. In loT business, a deep network with external organizations improves profitability.

Next we turn to organizational capability suitable for loT business, considering especially the capability for advancing open innovation.

According to previous research, in interorganizational relations, selective ability and integration capability are important. It is thought that loT business is still currently in an introductory period or 
growth phase, that is, a phase in which new technology, products, and services are being produced one after another. And the speed of this technological transition is clearly a character of IoT business. In such a transitional environment it is very difficult to select the candidate with which a company should associate. If selection is successful, the company's products and services may spread greatly, but the risk of making an incorrect selection is high.

It is thought that a high level of selective ability is very important. As compared with typical businesses, it is thought that there is much opportunity to select an external technology in which a company is inexperienced. Understanding the product or service beyond the company's own industry is also required. Furthermore, if a company has the ability to create a big future concept and to involve various external companies, it can advance business to its advantage. Therefore, it becomes important to expand the search organization and to heighten search capability. The areas of responsibility and authority for a person who can cooperate with external organizations probably also need to be expanded. Build-up of human capability, such as the employment of talented people with external relationship experience, is also required.

On the other hand, even if the company can select a desirable cooperation partner, the process capability to cooperate and successfully perform is also important. Especially in loT businesses, as compared to conventional businesses, it is thought necessary to carry out more complicated cooperation among more various external organizations. An opportunity for a company to tackle an uncertain technology challenge in a new field may also increase. It is thought that the integration/coordination ability to advance the cooperation process steadily against the uncertain technology challenges among external organizations becomes important. The resource mobilization and management capability for advancing the cooperation process certainly must be considered, as they can determine the success or failure of cooperation.

H5. In the open innovation of loT business, selection capability improves profitability.

H6. In the open innovation of loT business, integration capability improves profitability.

\section{Research methodology and synopsis}

\section{4-1. Research methodology}

A questionnaire was developed to verify these hypotheses. The questions were set up based on prior research and each hypothesis. Responses employed 5-point Likert scales. Candidates were limited to IT-related companies that undertake IoT business, so as to constrain the possibilities for confounding issues. Survey administration and data collection were entrusted to Macromill, an Internet questionnaire monitoring company.

\section{4-2. Survey synopsis}

The questionnaire first screened the potential respondents, of whom there were around 10,000 individuals, for several criteria. Only IT-related companies were included (information, communication, software, system integrator, IT solution, etc.). Companies needed to be utilizing the loT environment for development of new products and services, and to be building business systems with external cooperation. Required job descriptions included the manager, executive, or person in charge of the information system $R \& D$. Considering that it is a contactless survey to the 
Internet monitor, the valid response was screened very strictly. After removing outliers, there were 35 companies. The survey was conducted in July 2017.

\section{$5 \quad$ Result of the analysis}

Factor analyses were conducted first, using a principal factor method and varimax rotation, and factors whose eigen values were one or more were extracted. Next, the correlation analysis among the extracted factors was conducted. IBM SPSS 23 was used for the statistical analysis.

\section{5-1. Factor analyses}

First, responses about the profitability of each company were analysed. IT-related companies provide various products and services, and the profitability about each was asked. Two factors were extracted as a result of the factor analyses: 1) mission-critical task systems that use rather conventional IT applications, such as customer relationship management, supply chain management, and knowledge management; and 2) systems that consisted of connectivity (telecommunication network), such as devices with sensors, platforms (data storage data fitting and processing), and analytics (artificial intelligence analytical tools). The first factor was named the conventional IT factor and the second factor was named the loT-related factor.

Next, responses were analysed about the data capabilities for the sources of competitive advantage. Two factors were extracted as a result of conducting the factor analyses: 1) capabilities around data analysis, systems configuration, business analytics, and statistical analysis; and 2) internal and external data-collection capabilities, information storage capabilities, etc. The first factor was named the data analysis factor and the second factor was named the data acquisition factor.

Next, responses were analysed about the forms of open innovation. Two factors were extracted as a result of conducting the factor analyses: 1) industrial cluster, technology consortium, sharing economy, etc.; and 2) strategic partnership, supply-chain cooperation, mutual equipment investment, etc. The first factor was named the large open innovation factor, and the second factor was named the deep open innovation factor.

Finally, responses were analysed about the organizational capabilities, for which two factors were extracted: 1) data-collection capability of external organization, technology-trends inquiry capability, business concept capability, system-design capability, industry rule making, external recruitment of talent, etc.; and 2) information-exchange system with an alliance partner, negotiation capability with an alliance partner, organizational coordination capability, project management capability, etc. The first factor was named the selection capability factor and the second factor was named the integration capability factor.

\section{5-2. Correlation analysis}

A correlation analysis was conducted to produce a score for each factor. Specifically, correlation coefficients were computed for the factors about profitability and other issues. Table 1 shows the result of this analysis, described below. 
Table 1. Correlation analysis result

\begin{tabular}{|l|l|l|}
\hline & conventional IT & IoT related \\
\hline data analysis & $.467^{* *}$ & $.438^{* *}$ \\
\hline data acquisition & .077 & $.461^{* *}$ \\
\hline large open innovation & $.593^{* *}$ & .246 \\
\hline deep open innovation & .083 & $.478^{* *}$ \\
\hline selection capability & $.392^{*}$ & $.451^{* *}$ \\
\hline integration capability & .187 & .224 \\
\hline
\end{tabular}

$\left({ }^{*}: 1 \%\right.$ significance, ${ }^{*}: 5 \%$ significance)

\section{Consideration}

The hypotheses were considered based on the survey analyses.

The hypotheses about data acquisition capability and data analysis capability $(\mathrm{H} 1$ and $\mathrm{H} 2)$ were verified. Data analysis capability $(\mathrm{H} 2)$ correlated significantly with both conventional IT and IoT. On the other hand, data acquisition capability $(\mathrm{H} 1)$ correlated only with loT. The difference between a conventional IT business and new loT business was shown by the result of the analysis. One of the characteristics of loT-related businesses is utilizing the big data generated by various sensors. In terms of profit generation, it is thought that holding scarce big data causes differentiation.

The hypotheses about the form of open innovation ( $\mathrm{H} 3$ and $\mathrm{H} 4)$ were verified. While broad open innovation (H3) correlated with conventional IT, deep open innovation (H4) correlated with loT. This result of the analysis differed from the original hypothesis. For loT-related businesses, cooperation with a broader system and various types of technological knowledge are needed, compared with conventional IT businesses. But many external cooperative arrangements do not necessarily contribute to profit. Since loT-related business is still in the introductory period or growth phase of the product life cycle, $R \& D$ for associated technology has high uncertainty. If many external cooperative arrangements are carried out for technological developments of high uncertainty, business resources may break up and the probability of success may fall. Success probability may be improved by selecting an alliance partner carefully, concentrating technology resources and tackling development. On the other hand, for conventional IT businesses, the technical standard may already be established and the differentiation point of each company may also have been determined. In such a business environment, by entering into cooperation as broadly as possible, each company can expand its business and may be able to increase its profit.

The hypotheses about the organizational capability for loT-related business ( $\mathrm{H} 5$ and $\mathrm{H} 6)$ were verified. The selection capability $(\mathrm{H} 5)$ correlated with both conventional IT and IoT. On the other 
hand, integration capability $(\mathrm{H} 6)$ correlated with neither. The latter result differed from the original hypothesis. Both IT and IoT businesses are industries where transitions of the technical and management environments are rapid. Since the life cycle of a product is short, a short lead time from development to sale becomes a condition that improves profitability. Therefore, the judgment of a technology trend and the speed of decision making are important. Development styles that produce results one after another are preferable to long-term and continuous development styles. This is considered to be the same also in open innovation with external organizations. It may be desirable to carry out a product concept quickly, to select an alliance partner quickly, to judge success or failure quickly, and to either produce commercially or to withdraw.

Many products about which prior research on integration capability has argued are products with high uncertainty for R\&D, such as pharmaceutical products, which involve a long lead time, or products with complicated structure, like automobiles. Although there also has been prior research on IT-related products, it has mainly involved development of an integrative and complicated large-scale system like a mainframe system. Regarding today's IT- and loT-related products, standardization and modularization are progressing, as compared with the past. If the interface standard with other products is kept, there is little necessity for coordination and integration for the whole system. Therefore, individual product development may be breaking up on a small scale in many cases. Also in loT-related businesses, it is not necessary that the company in charge of a whole concept and the company in charge of each technological development be the same. It may be more desirable to specialize and to diversify the R\&D. If a company successfully combines its $R \& D$ style with external innovation, speed and efficiency may improve and profitability may become high.

Note that this may constitute a threat to the former type of Japanese firm. Prior research has pointed out that the integration/coordination capability of Japanese firms is generally high and the selection capability is low. Also in external cooperation, the favoured strategy was to complete a product deliberately on the basis of a long-term relationship. However, in loT-related businesses, it is thought that selective abilities, such as judgment and decision-making capabilities, are important. This is a challenge for many Japanese firms.

\section{Conclusion}

The purpose of this research was to quantitatively clarify the interorganizational relations and organizational capabilities that are suitable to the industry character of loT-related businesses. Moreover, we also proposed to look for the reasons why Japanese loT-related businesses are not necessarily successful.

In prior research, interorganizational relations and organizational capability were related to the success or failure of R\&D or profitability. Moreover, research has shown that the optimal interorganizational relations and organizational capabilities differed from each other according to the differences between industries, product characteristics, etc. As a result of conducting a survey about loT-related businesses, the character of the interorganizational relations and the organizational capabilities related to profitability in loT businesses became clear. The study also showed the challenge against organization management of the former type of Japanese firm.

One limitation of this research is a result of the questionnaire, regarding the credibility and validity of results by survey respondents, the number of samples, etc. Future research should extend the 
scope of such a survey internationally and longitudinally to observe serial transitions. Moreover, investigative methods other than a questionnaire should be conducted.

\section{Acknowledgment}

This work was supported by JSPS KAKENHI Grant Number 16 K03916.

\section{References}

Aoki, M. (2002), Modularization of industrial architecture: A theoretical introduction, In Aoki, M. and Ando H. (Eds.), Modularization: Nature of new industrial architecture. Tokyo: Toyo Keizai Shinposha, pp. 3-31.

Badaracco, J. (1991), The knowledge link: How firms compete through strategic alliances. Boston, MA: Harvard Business School Press.

Baldwin, C. Y. and Clark, K. B. (2000). Design rules: The power of modularity (Vol. 1). Cambridge, MA: MIT Press. https://doi.org/10.7551/mitpress/2366.001.0001

Chesbrough, H. W. (2003), Open innovation: The new imperative for creating and profiting from technology. Cambridge, MA: Harvard University Press.

Christensen, C. M. (1997). The innovator's dilemma: When new technologies cause great firms to fail. Boston, MA: Harvard Business School Press.

Christensen, J. F. (2006). Whither core competency for the large corporation in an open innovation world? In Chesbrough, H. W., Vanhaverbeke, W., and West, J. (Eds.). Open innovation: Researching a new paradigm. Oxford: Oxford University Press, pp. 35-61.

Coleman, J. S. (1988). Social capital in the creation of human capital. American Journal of Sociology, 94, pp. S95-S120. https://doi.org/10.1086/228943

Dittrich, K., Duysters, G., and de Man, A.-P. (2007). Strategic repositioning by means of alliance network: The case of IBM. Research Policy, 36(10), pp. 1496-1511. https://doi.org/10.1016/j.respol.2007.07.002

Dyer, J. and Kale, P. (2007). Relational capabilities: Drivers and implications. In Helfat, C. E., Finkelstein, S., Mitchell, W., Singh, H., Teece, D., and Winter S.G. (Eds.). Dynamic capabilities: Understanding strategic change in organizations. Malden, MA: Blackwell Publishing, pp. 65-79.

Dyer, J. H., and Singh, H. (1998). The relational view: Cooperative strategy and sources of interorganizational competitive advantage. Academy of Management Review, 23(4), pp. 660-679. https://doi.org/10.5465/amr.1998.1255632

Fujimoto T. and Nobeoka K. (2004). In Which Industries Does Japan Excel? The Compatibility between Architecture and Organizational Capability. RIETI Discussion Paper Series, 04-J-040, pp. 1-26 (in Japanese).

Goold, M. and Campbell A. (2002). Designing effective organizations: How to create structured networks. San Francisco, CA: Jossey-Bass.

Granovetter, M. (1973). The strength of weak ties. American Journal of Sociology, 78(6), pp. 1360-1380. https://doi.org/10.1086/225469

Granovetter, M. (2005). The impact of social structure on economic outcomes. Journal of Economic Perspectives, 19(1), pp. 33-50. https://doi.org/10.1257/0895330053147958 
Henderson, R. and Cockburn, I. (1994). Measuring competence? Exploring firm effects in pharmaceutical research. Strategic Management Journal, 15 (Winter), pp. 63-84. https://doi.org/10.1002/smj.4250150906

Hoffmann, H. W. and Schlosser R. (2001). Success factors of strategic alliances in small and medium sized enterprises: An empirical survey. Long Range Planning, 34(3), pp. 357-381. https://doi.org/10.1016/S0024-6301(01)00041-3

Iansiti, M. and Clark, K. B. (1994). Integration and dynamic capability: Evidence from product development in automobiles and mainframe computers. Industrial and Corporate Change, 3(3), pp. 557-605. https://doi.org/10.1093/icc/3.3.557

Imai, K., Itami, H., and Koike, K. (1982). Economics of internal organization. Tokyo: Toyokeizai Shinposha (in Japanese).

Krackhardt, D. (1992). The strength of strong ties: The importance of philos in organizations. In: Nohria, N. and Eccles, R. (Eds.), Networks and organizations: Structure, form, and action. Boston, MA: Harvard Business School Press, pp. 216-239.

Langlois, R. N. and Robertson, P.L. (1992). Networks and innovation in a modular system: Lessons from the microcomputer and stereo component industries. Research Policy, 21(4), pp. 297-313. https://doi.org/10.1016/0048-7333(92)90030-8

Levinthal, D. and March, J. (1993). The myopia of learning. Strategic Management Journal, Vol.14, pp. 95112. https://doi.org/10.1002/smj.4250141009

March, J. G. (1991), “Exploration and exploitation in organizational learning”, Organization Science, 2(1), pp. 71-87. https://doi.org/10.1287/orsc.2.1.71

Porter, M. E., and Heppelmann, J. E. (2014). How smart, connected products are transforming competition. Harvard Business Review, 92(11), pp. 64-88.

Porter, M. E., and Heppelmann, J. E. (2015). How smart, connected products are transforming companies. Harvard Business Review, 93(10), pp. 96-114.

Powell, W. W., Koput, K. W., and Smith-Doerr, L. (1996). Interorganizational collaboration and the locus of innovation: Networks of learning in biotechnology. Administrative Science Quarterly, 41(1), pp. 116145. https://doi.org/10.2307/2393988

Raisch, S., Birkinshaw, J., Probst, G., and Tushman M. L. (2009). Organizational ambidexterity: Balancing exploitation and exploration for sustained performance. Organization Science, 20(4), 685-695. https://doi.org/10.1287/orsc.1090.0428

Stuart, T. E. and Podolny, J. M. (1996). Local search and the evolution of technological capabilities. Strategic Management Journal, 17, pp. 21-38. https://doi.org/10.1002/smj.4250171004

Ulrich, K. (1995). The role of product architecture in the manufacturing firm. Research Policy, 24(3), pp. 419-440. https://doi.org/10.1016/0048-7333(94)00775-3

Uzzi, B. (1997). Social structure and competition in interfirm networks: The paradox of embeddedness. Administrative Science Quarterly, 42(1), pp. 35-67. https://doi.org/10.2307/2393808 